\title{
Cutaneous leishmaniasis: Comparative Techniques for Diagnosis
}

\author{
*Aya R. Al-Heany BSc; MSc. ,**Professor Khalifa E. Sharquie MD; PhD, \\ *** Professor Sabah A. Al-Najar BSc; MSc., ****Assist. Prof. Adil A. Noaimi \\ MD; DDV; FICMS. \\ * Department of Microbiology, \\ **Scientific Council of Dermatology and Venereology Department-Iraqi Board for Medical Specializations. \\ *** Department of Microbiology, college of medicine, Baghdad University. \\ **** Department of Dermatology and Venereology, college of medicine, Baghdad university.
}

\begin{abstract}
:
Background: Cutaneous leishmaniasis is a major public health problem as a disease endemic in Iraqi population. Many diagnostic tools are used to establish the diagnosis like smear, histopathology and culture.

Objectives: To find more rapid, sensitive and specific diagnostic method, to establish the diagnosis of cutaneous leishmaniasis.

Patients and methods: Sixty patients with clinical diagnosis of cutaneous leishmaniasis were included in present work during the period between December / 2012 to May / 2013 in Department of Dermatology in Baghdad Teaching Hospital, Al-Yarmook Teaching Hospital and Al-Karama Teaching Hospital and Microbiology Department in collage of Medicine / University of Baghdad. The following diagnostic techniques were carried out for diagnosis of cutaneous leishmaniasis including dental broach smear, histopathology examination and culture on Roswell park medium institute (RPM I 1640) and on NNN media. In addition to PCR technique was performed for all patients.

Sixty patients with other skin lesions were processed for PCR as a control group.

Results: Sixty patients with cutaneous leishmaniasis, 39 males and 21 females with range age from 6 months to 55 years with a median 24 years. The results of diagnostic techniques were as follow: dental broach smear positive in 41 (68.33\%), histopathology in 6(27.27\%), culture in 45(75\%) and the PCR positive in 55 (91.66\%) patients. By PCR, the study differentiated Leishmania major (60\%) and Leishmania tropica (40\%). PCR was the most sensitive (91.66\%) and specific (100\%) technique when compared with other diagnostic techniques.

Conclusion: In conclusion, PCR differentiated two species of Leishmania in Iraq, 60\% Leishmania major and 40\% Leishmania tropica and it was the most sensitive and specific diagnostic test in cutaneous leishmaniasis.
\end{abstract}

\section{Introduction}

Cutaneous leishmaniasis (CL) a vector-borne parasitic disease is a widespread and may causes serious health problems in the communities throughout the mediterranean regions and the Middle East, including Iraq ${ }^{(1)}$.

The diagnostic methods available at present are mostly based on clinical and epidemiological evidence and parasite detection. So far, no single laboratory method has been accepted as a gold standard for diagnosis CL. Parasitological tests of a skin biopsy specimen are not always conclusive in patients with a clinical diagnosis of $\mathrm{CL}^{(2)}$. Tissue sampling using dental broach and stained with Giemsa stain although is a simple technique but always need personal experience in order to find the parasite in the smear. As the parasites are located in the smear in loci and not in uniform pattern and the positivity rate from $(54.33-71.6 \%)^{(3,4)}$. Still tissue sampling by dental broach is useful for culturing procedure. Biopsies and staining with $\mathrm{H} \& \mathrm{E}$ stains is also a useful to see the LD bodies and to detect the parasite and the positivity rate from $(10.1-30 \%)^{(5,4)}$. Culturing of the parasite is very specific \& sensitive technique but it is a time consuming and the positivity rate from $(52.9-80 \%)^{(6,4)}$.

Modern molecular characterization techniques have used the polymerase chain reaction (PCR) to amplify parasite DNA from host tissues. PCR-based methods, as a powerful tool to detect Leishmania directly in clinical samples as well as for parasite characterization, have proven to be highly sensitive and specific compared with traditional methods ${ }^{(7)}$ and providing results in one or two working days ${ }^{(8)}$. With the advances in molecular techniques, a number of molecular markers and PCR protocols for the detection or identification of Leishmania on different taxonomical levels (genus, complex, and species) has been reported ${ }^{(9)}$. Target sequences for characterization include either nuclear DNA, such as the small subunit rRNA (ssu rRNA) gene ${ }^{(10)}$ , a repetitive genomic sequence ${ }^{(11)}$, the mini-exon (spliced leader) gene repeat ${ }^{(12)}$, the beta-tubulin gene region, the gp63 gene locus ${ }^{(13)}$, and internal transcribed spacer (ITS) regions ${ }^{(9,14)}$; microsatellite DNA; or kinetoplast DNA, such as minicircle sequences ${ }^{(15)}$. Among targets applied in DNA-based methods, mini-exon is highly specific and sensitive because the gene is present in all Kinetoplastida, whereas absent from the 
vertebrate host or invertebrate vector. Moreover, different Leishmania species have distinct length of the nontranscribed intergenic spacer region ${ }^{(16)}$.

\section{Materials \& Methods}

Sixty patients with CL were enrolled in the present work during the period between December / 2012 to May / 2013 that sample from Baghdad, AL-Yarmook, AL-Karamaa Teaching Hospitals.

All the demographic feature of the diseases, were recorded. Sixty patients with different skin diseases were taken as a control group. Biopsies from these lesions were processed for PCR as a control for CL.

The following diagnostic techniques were performed from the lesions of leishmaniasis in all patients; dental broach tool was used to do smears that processed for Giemsa stain. Skin biopsies were performed with hematoxylin \& eosin and leishman stains.

The tissue obtained by dental broach tool and biopsies were cultured on RPMI 1640 \& on NNN media, while PCR was done for all patients from biopsies and culture material as follow:

\section{DNA extraction}

DNA was extracted by using MagaZorb®® DNA Mini-Prep Kit (promega, USA) according to the manufactures instruction.

\section{PCR amplification}

Amplification of the mini-exon gene was performed as a single PCR with forward primer (F -5'-

TATTGGTATGCGAAACTTCCG-'3) and reverse primer (R- 5'-ACAGAAACTGATACTTATATAGCG'-3) (promega, USA) primers as described before ${ }^{(17)}$.

Three $\mu$ l of template DNA were amplified in $12.5 \mu$ l Green Master Mix (promega, USA) with $7.5 \mu$ l NucleaseFree Water and $1 \mu 1$ of each primer. DNA was amplified using thermal cycler (PeQlab primus, USA) under the following conditions were $5 \mathrm{~min}$ at $95 \mathrm{C}^{\circ}$ followed by 35 cycles of $30 \mathrm{sec}$ at $95 \mathrm{C}^{\circ}, 30 \mathrm{sec}$ at $53 \mathrm{C}^{\circ}$, and $30 \mathrm{sec}$ at $72 \mathrm{C}^{\circ}$ followed by 1 cycle of $20 \mathrm{~min}$ at $72 \mathrm{C}^{\circ}$. PCR products were separated on $1.5 \%$ agarose gel.

\section{Statistical Analysis}

The data were analyzed by using Microsoft Excel 2007 and SPSS version 18. The Chi-square test was used to compare of differences between study groups.

The sensitivity and specificity indexes were estimated to compare among many diagnosis methods.

The significance level was set as $5 \%, \mathrm{P}<0.05$ was considered significant.

\section{Results}

A total of 60 patients with clinical diagnosis of CL were $65 \%$ males and 35\% females. The median age was 24 years (range from 6 months to 55 years). It was found that $66.67 \%$ (40 cases) had multiple lesions, while $33.33 \%$ (20 cases) had single lesion. The highest number of skin lesions per case was 18 . The total number of skin lesions in all CL patients was 200; of these, 36 cases $(60 \%)$ had wet skin lesion while 24 case $(40 \%)$ had dry skin lesion. Table 1 shows the differences of positive results between different methods and type of lesions; these results were statistically significant $\mathrm{P}<0.05$, apart of the differences between dry and wet lesion in each method were statistically not significant $\mathrm{P}>0.05$.

Hence, the sensitivity of different techniques was as follow: - the dental broach smear was (68.3\%), the histopathological section was (27.27\%), the culture was (75\%) and the PCR was (91.66\%), (Table 2).

While, the specificity of these techniques, when the culture was used as a gold standard and compared with other methods, was as follow: - the dental broach smear was (75.55\%), histipathological section was (50\%), and PCR was (100\%), (Table 3).

Table 1. The type of lesion in relation with different methods for detection of cutaneous leishmaniasis

\begin{tabular}{|c|c|c|c|c|c|c|c|c|c|c|}
\hline \multirow{3}{*}{ Type of lesion } & \multicolumn{10}{|c|}{ Methods** } \\
\hline & \multicolumn{2}{|c|}{ Dental broach smear } & \multicolumn{2}{|c|}{ culture } & \multicolumn{2}{|c|}{ Histopathology } & \multicolumn{2}{|c|}{ PCR } & \multirow[t]{2}{*}{ Chi-square $^{*}$} & \multirow[t]{2}{*}{ P. value * } \\
\hline & $\begin{array}{l}\mathrm{Ye}+ \\
(\%)\end{array}$ & $\begin{array}{l}\text { Ye } \\
(\%)\end{array}$ & $\begin{array}{l}\mathrm{Ve}+ \\
(\%)\end{array}$ & $\begin{array}{l}\text { Ve } \\
(\%)\end{array}$ & $\begin{array}{l}\mathrm{Ye}+ \\
(\%)\end{array}$ & $\begin{array}{l}\text { Ye } \\
(\%)\end{array}$ & $\begin{array}{l}\mathrm{Ve}+ \\
(\%)\end{array}$ & $\begin{array}{l}\text { Ve- } \\
(\%)\end{array}$ & & \\
\hline Dry* & $\begin{array}{c}16 \\
66.66 \%\end{array}$ & $\begin{array}{c}8 \\
33.33 \%\end{array}$ & $\begin{array}{c}18 \\
75 \%\end{array}$ & $\begin{array}{c}6 \\
25 \%\end{array}$ & $\begin{array}{c}2 \\
25 \%\end{array}$ & $\begin{array}{c}6 \\
75 \%\end{array}$ & $\begin{array}{c}21 \\
87.5 \%\end{array}$ & $\begin{array}{c}3 \\
12.5 \%\end{array}$ & 11.86 & 0.0078 \\
\hline Wet $^{*}$ & $\begin{array}{c}25 \\
69.44 \%\end{array}$ & $\begin{array}{c}11 \\
30.55 \%\end{array}$ & $\begin{array}{c}27 \\
75 \%\end{array}$ & $\begin{array}{c}9 \\
25 \%\end{array}$ & $\begin{array}{c}4 \\
28.57 \%\end{array}$ & $\begin{array}{c}10 \\
71.42 \%\end{array}$ & $\begin{array}{c}34 \\
94.44 \%\end{array}$ & $\begin{array}{c}2 \\
5.55 \%\end{array}$ & 23.11 & $<0.0001$ \\
\hline
\end{tabular}


Cutaneous leishmaniasis: Comparative Techniques for Diagnosis

Table 2. The sensitivity of different techniques used in detection of cutaneous leishmaniasis in patients group

\begin{tabular}{|c|c|c|c|c|}
\hline Methods & +ve & -Ve & total & sensitivity \\
\hline $\begin{array}{c}\text { Dental broach } \\
\text { Smear }\end{array}$ & 41 & 19 & 60 & $68.3 \%$ \\
\hline Culture & 45 & 15 & 60 & $75 \%$ \\
\hline Histopathology & 6 & 16 & 22 & $27.27 \%$ \\
\hline PCR & 55 & 5 & 60 & $91.66 \%$ \\
\hline
\end{tabular}

Table 3. The specificity of different technique used in diagnosis of cutaneous leishmaniasis in patients group

\begin{tabular}{|c|c|}
\hline Methods & Specificity \\
\hline Dental broach smear & $75.55 \%$ \\
\hline Culture & $100 \%$ (gold standard) \\
\hline Histopathology & $50 \%$ \\
\hline PCR & $100 \%$ \\
\hline
\end{tabular}

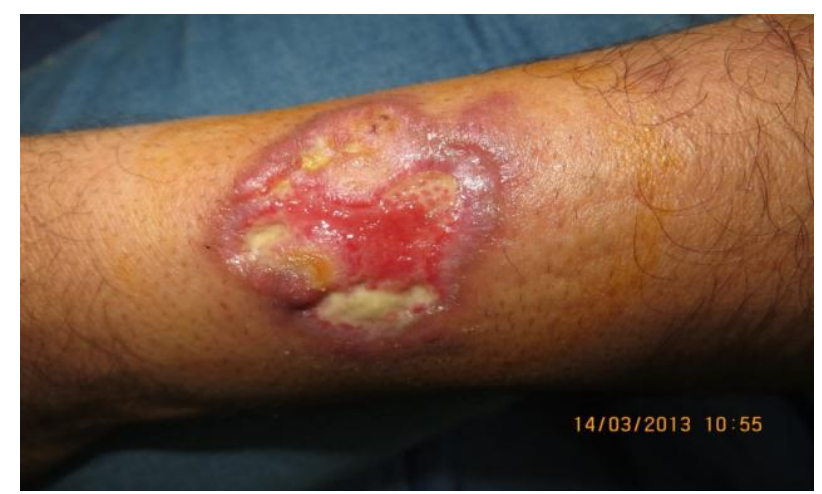

Figure 1. Twenty five years old male, showing ulcerative skin lesion of leishmaniasis in the left fore arm.

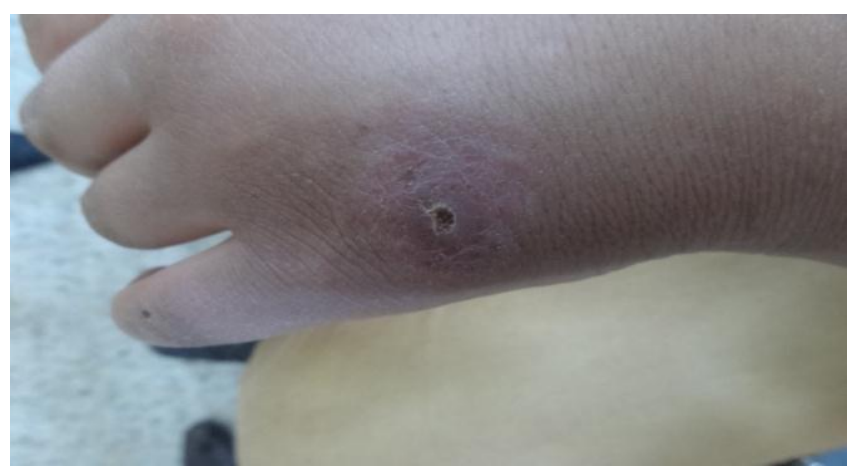

Figure 2. Eighteen years old male showing dry skin lesion of leishmaniasis on the dorsum of the left hand.

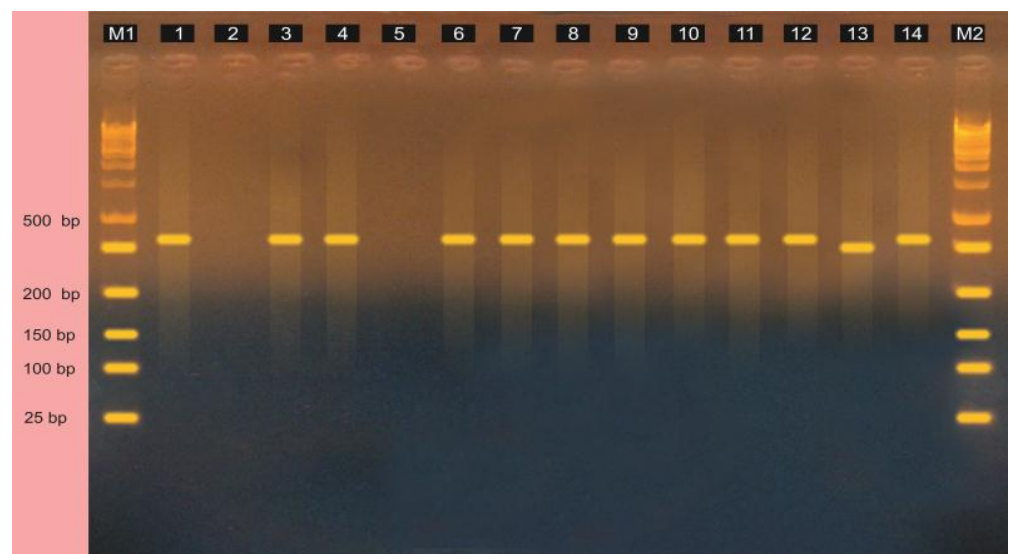

Figure 3. PCR products of mini-exon gene of Leishmania species from patients group, on 1.5\% agarose gel, M1 \& M2 molecular marker 1Kbp (1000-25 bp), Lane 1 positive control; Lane 2: negative control (distil water 
instead of DNA template); Lanes (3-14): samples, with voltage 100 for 30 min. Lanes $(3,4,6,7,8,9,11,12,14)$ : positive samples L major at M.W. 430 bp; Lane 13: positive sample L. tropica at M.W. 400bp.

\section{Discussion}

Cutaneous leishmaniasis is an old endemic disease in Iraq. The disease may originate in central Asia and was transported to Iraq either by Mongol invaders or by national extension ${ }^{(18)}$.

Diagnosis of CL is mainly by a clinical one, which as a classical characteristic morphological picture. There are many laboratory tests that help in diagnosis of CL. PCR although not available in all center, but might more sensitive and specific in compares with other diagnostic tests.

In the present study, we report the first application of mini-exon PCR in order to characterize the Leishmania species causing cutaneous leishmaniasis in Iraq.

In the present study, dry skin lesion was $24(40 \%)$ and wet skin lesion was $36(60 \%)$ with significant differences between different diagnostic methods of CL. with the type of lesions. These results were in agreement with many studies in Iraq ${ }^{(19)}$ Afghnistan ${ }^{(20)}$, Iran ${ }^{(21)}$, Colombia ${ }^{(22)}$, but disagreement with other study done in India ${ }^{(23)}$. The high frequency of wet lesions may be due to the presence of reservoir animals in large number in some areas in Iraq especially rodents and dogs ${ }^{(19)}$.

The present study showed the sensitivity of different techniques used in diagnosis of CL. When the present work compare with other Iraqi studies, the results were comparable as follows, the sensitivity of dental broach smear in our study $(68.33 \%)$ was in agreement with other result $(71.6 \%)$ done in Iraq by Sharquie et $\mathrm{al}^{(4)}$, the sensitivity of culture method $75 \%$ was in agreement with other study done in Iraq by Sharquie et $\mathrm{al}^{(4)}(80 \%)$, while the sensitivity of culture method was disagreement with the result obtained by Al-Samaria and Al-Obaidi (19) $(43 \%)$. This may be due to the difference in number of patients in these studies. The sensitivity of histopathological section $(27.27 \%)$ was in agreement with the results of Sharquie et al ${ }^{(4)}$ was $(30 \%)$ and disagreement with Anwer et al ${ }^{(5)}(10.1 \%)$.

According to the best of our knowledge, we report the first time application of mini-exon PCR in order to characterize the Leishmania species causing cutaneous leishmaniasis in Iraq. In this study the sensitivity of PCR was $91.66 \%$, in comparable with other results in other countries, Palestine ${ }^{(7,23)}$. the difference was statically not significant. In this study the miniexon PCR assay was more sensitive than the conventional diagnostic methods and capable of detecting infection in a wide range of clinical samples.

The present study showed the PCR was more specific technique for diagnosis of cutaneous leishmaniasis with $(100 \%)$ specificity; this result was in agreement with Marfurt et al ${ }^{(23)}$. Followed by dental broach smear was $(75.55 \%)$ specificity, while the specificity of histopathology was (50\%).

Results in figure (3) showed the two types of Leishmania spp., in Iraq, by using mini-exon PCR assay, $L$. major $(60 \%)$ and L. tropica $(40 \%)$ and this in agreement with other Iraqi study ${ }^{(24)}$ and other study in nearby countries such as Iran ${ }^{(25)}$, hence the high incidence of $L$. major may be due to the presence of reservoir animals in large numbers, especially rodents and dogs (reservoir of $L$. major). Obviously, dense populations of natural hosts of $L$. major, together with abundant vector sand flies, are the key elements responsible for the high rate of human infection.

In conclusion, the sensitivity of diagnostic tests was as follow: - the dental broach smear was (68.3\%), the histopathological section was $(27.27 \%)$, the culture was $(75 \%)$ and the PCR was $(91.66 \%)$. And the specificity of these tests was as follow: - (75.55\%), (50\%), and (100\%) respectively.

PCR was the most rapid, sensitive and specific test for diagnosis of cutaneous leishmaniasis.

\section{References}

[1]. CDC (2004) Update CL in US. Military personnel. Southwest / Central Asia, 2002-2004. MMWR 53:264-265.

[2]. Schalling HDFH, Oskam L (2002) Review: molecular biological applications in the diagnosis and control of leishmaniasis and parasite identification. Trop Med Int Health 7: 641-651.

[3]. Gazozai S. U., Iqbal J. , Bukhari I., and Bashir S., (2010): "Comparison of diagnostic methods in cutaneous leishmaniasis (histopathology compared to skin smears)," Pakistan Journal of Pharmaceutical Sciences, vol. 23, no. 4, pp. $363-366$.

[4]. Sharquie KE, Al-Waiz M, Al-Hammamy H. (2002): Post Kala-Azar Dermal Leishmaniasis in Iraq Children. J Fac Med. (Baghdad); 44:4.

[5]. Anwer M., Hussain M. A., Ur-Rehman H., et al. (2007): Epidemic of cutaneous leishmaniasis: 109 cases in a population of 500, Eastern Mediterranean Health Journal, vol. 13, no. 5, pp. 1212-1215

[6]. Khosravi S., Hejazi S.H., Hashemzadeh M., Eslami G., and Darani HY.( 2012): Molecular diagnosis of old world leishmaniasis: realtime PCR based on tryparedoxin peroxidase gene for the detection and identification of Leishmania spp. Vector Borne Dis; 49: 15-18

[7]. Bensoussan E, Nasereddin A, Jonas F, Schnur LF., et al. (2006): Comparison of PCR assays for diagnosis of cutaneous leishmaniasis. J Clin Microbiol; 44(4): 1435-9.

[8]. Foulet F, Botterel F, Buffet P, et al. (2007): Detection and identification of Leishmania species from clinical specimens by using a real-time PCR assay and sequencing of the cytochrome B gene. J Clin Microbiol.; 45:2110-2115.

[9]. Nasereddin A, Bensoussan E, Scho“ nian G, et al. (2008): Molecular diagnosis of Old World Leishmaniasis and species identification by use of a reverse line blot hybridization assay. Journal of Clinical Microbiology 46, 2848-2855.

[10]. Gomes AHS, Armelin IM, Menon SZ, Pereira-Chioccola VL (2008) Leishmania (V.) braziliensis: detection by PCR in biopsies from patients with cutaneous leishmaniasis. Exp Parasitol 119:319-324. 
[11]. Akkafa F, Dilmee F, Alpua Z (2008): Identification of Leishmania parasites in clinical samples obtained from cutaneous leishmaniasis patients using PCR-RFLP technique in endemic region, Sanliurfa province, in Turquey. Parasitol Res 103:583-586.

[12]. Serin, M.S., Daglioglu, K., Bagirova, M., et al. (2005): Rapid diagnosis and genotyping of Leishmania isolates from cutaneous and visceral leishmaniasis by microcapillary cultivation and polymerase chain reactionrestriction fragment length polymorphism of miniexon region. Diagn.Microbiol. Infect. Dis. 53, 209-214.

[13]. Victor K, Banuls AL, Arevalo J, Llanos A, Hamers R, Noel S, et al. (1998). The gp63 gene locus, a target for genetic characterization of Leishmania belonging to subgenus. Viannia Parasitol, 117(1):1-13.

[14]. Schönian G, Nasereddin A, Dinse N, Schweynoch C, Schallig HD, et al. (2003) PCR diagnosis and characterization of Leishmania in local and imported clinical samples. Diagn Microbiol Infect Dis 47: 349-358

[15]. Tojal da Silva A, Cupolillo E, Volpini A, Almeida R, Romero G 2006. Species diversity causing human cutaneous leishmaniasis in Rio Branco, state of Acre, Brazil. Trop Med Int Health 11: 1388-1398.

[16]. Fernandes O, Murthy VK, Kurath U, et al. (1994): Miniexon gene variation in human pathogenic Leishmania species. Mol Biochem Parasitol.; 66(2):261-71.

[17]. Saki J., Meamar AR. , Oormazdi H., et al.( 2010): Mini-Exon Genotyping of Leishmania Species in Khuzestan Province, Southwest Iran, Iranian J Parasitol:, Vol. 5, No.1, pp. 25-34.

[18]. Farah FS, Malak JA. (1971): Cutaneous leishmaniasis. Arch Dermatol; 103:467-474.

[19]. AlSamarai AM, AlObaidi HS. (2009): Cutaneous leishmaniasis in Iraq. J Infect Dev Ctries. 3(2):123-9.

[20]. Faulde M, Schrader J, Heyl G, Amirih M (2008) Differences in transmission seasons as an epidemiological tool for characterization of anthroponotic and zoonotic cutaneous leishmaniasis in northern Afghanistan. Acta Tropica 105:131-138

[21]. Talari SA, Shajari G, Talaei R (2006) Clinical finding of cutaneous leishmaniasis as a new focus of Iran. Internet J Infec Dis 1 (2).

[22]. Ramirez JR, Agudelo S, Muskus C, et al. (2000) Diagnosis of cutaneous leishmaniasis in Colombia: the sampling site within lesions influences the sensitivity of parasitologic diagnosis. J Clin Microbiol 38:3768-3773.

[23]. Singh S and Sivakumar R (2003) Recent advances in the diagnosis of leishmaniasis. JPGM 55-60.

[24]. Marfurt J, Nasereddin A, Niederwieser I, et al. (2003): Identification and differentiation of Leishmania species in clinical samples by PCR amplification of the Miniexon Sequence and Subsequent Restriction Fragment Length Polymorphism Analysis. J Clin Microbiol 41(7):3147-3153.

[25]. Rahi A.A.; Nsaif S.; Hassoni J.J. et al Comparison of diagnostic methods in Cutaneous Leishmaniasis in Iraq: 2013; A. j. bio. 1(1): 15 . 